\title{
PENGARUH KOMITMEN PROFESIONAL DAN KEPUASAN KERJA TERHADAP TURNOVER INTENTION (Studi Empiris pada Kantor Akuntan Publik di Jawa Timur)
}

\author{
Oleh: \\ Putri Awalina \\ Dosen Akuntansi, Universitas Islam Kadiri, Kediri \\ Email: putriawalinajaw@gmail.com
}

\begin{abstract}
ABSTRAK
Penelitian ini bertujuan untuk membuktikan pengaruh komitmen profesional dan kepuasan kerja terhadap turnover intention. Variable komitmen profesional terdiri dari tiga dimensi yaitu Affective Professional Commitment, Continuance Professional Commitment, dan Normative Professional Commitment. Penelitian ini menggunakan metode survei dalam pengambilan data dan diolah dengan menggunakan smartPLS.Hasil penelitian ini adalah turnover intention pada KAPditentukan oleh komitmen profesional yang terdiri dari affective professional commitment dan continuance professional commitment, serta kepuasan kerja auditor. Penelitian ini tidak berhasil membuktikan bahwa turnover intention ditentukan oleh normative professional commitment.
\end{abstract}

Kata kunci: Affective Professional Commitment, Continuance Professional Commitment, Normative Professional Commitment, Kepuasan Kerja, Turnover Intention

\begin{abstract}
This study is aimed at investigating the influence of professional commitment and job satisfaction towards turnover intention. The professional commitment variable consists of three dimensions, which are Affective Professional Commitment, Continuance Professional Commitment, and Normative Professional Commitment. This study employed survey for the data collection and the data collected was then analyzed by using smart PLS. The finding of this study shows that turnover intention is determined by professional commitment which consists of affective professional commitment and continuance professional commitment, as well as auditor's job satisfaction.However, this study fails to prove that turnover intention is defined by normative professional commitment.
\end{abstract}

Keywords: Affective Professional Commitment, Continuance Professional Commitment, Normative Professional Commitment, Job Satisfaction, Turnover Intention.

\section{PENDAHULUAN}

Sumber daya manusia merupakan hal terpenting di sebuah perusahaan atau organisasi yang dapat mempengaruhi efisiensi dan efektifitas organisasi. Oleh karena itu, penting memperhatikan tingkat kompetensi, profesionalisme, komitmen, serta kepuasan kerja karyawan terhadap bidang yang ditekuninya. Kepuasan kerja dan komitmen merupakan sikap dan perilaku yang dipandang sebagai penggerak dari motivasi seseorang untuk bekerja yang saling terkait erat (Trisnaningsih, 2001). 
Komitmen yang dimiliki akan menjadi penggerak seseorang untuk melakukan pekerjaan dengan baik, sehingga dapat mencapai kepuasan yang maksimal. Namun, saat ini sulit mendapatkan sumber daya manusia yang berkompetensi dan berkomitmen, terlebih lagi mempertahankan yang sudah ada.

Keinginan berpindah atau sering disebut dengan turnover intention merupakan niat individu untuk mencari alternatif pekerjaan lain (Pasewark \& Strawse, 1996). Fenomena yang banyak terjadi adalah karyawan mengundurkan diri pada saat masa kerja yang baru beberapa tahun. Sehingga seringkali profesi disuatu perusahaan hanya digunakan sebagai batu loncatan sebelum beralih ke profesi yang lain. Fenomena turnover intention pada profesi auditor telah diamati oleh peneliti. Hasil yang didapatkan berdasarkan pengamatan peneliti adalah selama satu tahun bahkan belum ada satu tahun bekerja banyak auditor baru yang memilih untuk resign dan mencari alternatif pekerjaan lain. Beberapa alasan yang diungkapkan oleh auditor yang memutuskan untuk resign adalah sistem kerja yang kurang memperhatikan kebutuhan auditor, gaji yang kurang memadai bila dibandingkan dengan pekerjaan yang dilakukan, serta image yang kurang memuaskan ketika auditor hanya bekerja pada KAP lokal. Oleh karena beberapa hal tersebut, sangat memungkinkan bagi auditor untuk memilih alternatif pekerjaan yang lain.

Beberapa kasus tertentu turnover diperlukan oleh perusahaan terhadap karyawan yang berkinerja rendah (Hollenbeck \& Williams, 1986 ; Toly, 2001). Namun tingkat turnover tersebut seharusnya tidak terlalu tinggi, sehingga perusahaan masih memiliki kesempatan untuk memperoleh manfaat atas peningkatan kinerja karyawan yang telah direkrutnya (Toly, 2001). Oleh karena itu, turnover intention harus disikapi sebagai suatu fenomena yang penting dalam kehidupan berorganisasi mengingat hal tersebut berpengaruh terhadap organisasi (Robbins \& Pujaatmaka, 1996: 25).

Beberapa penelitian telah menemukan penyebab berpindahnya karyawan dari profesinya. Komitmen profesional yang rendah pada karyawan menjadi salah satu faktor keinginan berpindah (Bline et al. 1991; Smith \& Hall, 2008). Selain itu situasi kerja yang tidak sesuai dengan harapan atau adanya pengaruh untuk mendapatkan alternatif pekerjaan lain dan kepuasan yang lebih baik juga mendorong seorang karyawan untuk berpindah (Bline et al, 1991; Kalbers \& Cenker, 2007; Utami \& Bonosyeani, 2009).

Penelitian Smith \& Hall (2008), Kalbers \& Cenker (2007) serta Bline et al. (1991) menyatakan bahwa turnover intention yang terjadi merupakan pengaruh dari kurangnya komitmen profesional. Lain halnya dengan Cho \& Huang (2012) yang menunjukkan hasil berbeda yaitu turnover intention tidak dipengaruhi oleh komitmen profesional karena sifat dari komitmen dapat berubah sepanjang waktu.

Penelitian Bline et al. 1991; Kalbers \& Cenker, 2007; Utami \& Bonosyeani, 2009; Pakawaru, 2009; Poznanski \& Bline,1997 menunjukkan hasil bahwa turnover intention dipengaruhi oleh kepuasan kerja. Namun dilain pihak, penelitian Toly (2001) menunjukkan bahwa turnover intention tidak dipengaruhi oleh kepuasan kerja karena seorang karyawan yang memiliki kepuasan kerja rendah masih belum sampai pada pemikiran untuk meninggalkan perusahaan.

Penelitian tentang turnover intention sangat menarik untuk dilakukan mengingat tingginya turnover intention yang merugikan organisasi maupun profesi. Penelitian ini adalah pengembangan penelitian Bline et al (1991) dengan menggabungkan variabel 
dari penelitian Smith \& Hall (2008). Ada beberapa perbedaan penelitian ini dengan penelitian sebelumnya. Pertama, penelitian sebelumnya Bline et al. (1991) menggunakan unidimensi dalam komitmen profesional, sedangkan dalam penelitian ini menggunakan multidimensi komitmen profesional yaitu (1) Affective Professional Commitment (APC), (2) Continuance Professional Commitment (CPC), dan (3) Normative Professional Commitment (NPC) yang diadopsi dari penelitian Smith \& Hall (2008). Hal tersebut dikarenakan alasan komitmen setiap individu tidaklah sama dalam suatu profesi, sehingga beberapa karyawan yang mempunyai kesetiaan tinggi untuk bertahan pada pekerjaannya kemungkinan memiliki alasan yang berbeda.

Tujuan dari penelitian ini adalah untuk membuktikan pengaruh komitmen profesional dan kepuasan kerja terhadap turnover intention. Hasil penelitian ini memberikan kontribusi pada pengembangan teori akuntansi keperilakuan yaitu teori motivasi. Berdasarkan hasil penelitian ini dapat diketahui bahwa motivasi karyawan untuk tetap bertahan dalam perusahaan atau KAP adalah komitmen profesional yang dimiliki serta kepuasan kerja dari karyawan. Selain itu, hasil penelitian ini dapat menjadi masukan bagi perusahaan atau KAP untuk meningkatkan kepuasan kerja dan menumbuhkan komitmen profesional pada karyawan untuk menekan adanya keinginan berpindah.

\section{TINJAUAN PUSTAKA DAN PENGEMBANGAN HIPOTESIS PENELITIAN}

\section{Hubungan antara Komitmen Profesional dengan Turnover Intention}

Komitmen menunjukkan hasrat karyawan sebuah perusahaan dalam hal ini adalah auditor untuk tetap tinggal dan mengabdi pada KAP dimana ia bekerja
(Amilin \& Dewi, 2008). Komitmen didefinisikan sebagai suatu keadaan seorang karyawan memihak pada suatu profesi atau organisasi tertentu beserta tujuan-tujuannya dan berniat memelihara keanggotaan dalam profesi maupun organisasi (Robbins, 2001: 140; Smith \& Hall, 2008). Dengan demikian komitmen sangat diperlukan dalam kelangsungan hidup perusahaan.

$\begin{array}{cccr}\text { Smith } & \& & \text { Hall (2008) } \\ \text { mengemukakan } & \text { tiga } & \text { dimensi } & \text { dari }\end{array}$ komitmen profesional yaitu Affective Professional Commitment (APC), terjadi ketika karyawan ingin menjadi bagian dari organisasi tersebut, karena adanya ikatan emosional. Dimensi yang kedua adalah Continuance Professional Commitment (CPC), merupakan kemauan individu untuk tetap bertahan dalam profesinya karena ia merasa tidak ada alternatif pekeraan lain. Dimensi ketiga adalah Normative Professional Commitment (NPC), dalam dimensi ini individu akan bertahan terhadap profesi mereka karena adanya kesadaran bahwa berkomitmen merupakan suatu keharusan bagi mereka.

Penelitian yang dilakukan oleh Bline etal. (1991) menunjukkan hubungan negatif antara komitmen profesional dengan turnover intention. Semakin tinggi komitmen karyawan terhadap profesinya maka turnover intention atau keinginan untuk berpindah akan semakin kecil, begitu pula sebaliknya jika komitmen profesional semakin rendah, maka keinginan untuk berpindah semakin kuat. Hal tersebut sesuai dengan pernyataan Amilin \& Dewi (2008) bahwa komitmen menunjukkan hasrat seorang karyawan untuk tetap tinggal dan mengabdi kepada perusahaan.

Berbeda halnya dengan hasil penelitian Bline etal. (1991), penelitian yang dilakukan oleh Smith \& Hall (2008) dan Kalbers \& Cenker (2007) menemukan hubungan yang lebih kuat antara APC dengan turnover intention 
daripada hubungan CPC dan NPC terhadap turnover intention. Hal tersebut menunjukkan bahwa jika ikatan emosional karyawan terhadap perusahaan rendah maka turnover intention semakin kuat, begitu pula sebaliknya jika ikatan emosional terhadap perusahaan tinggi maka turnover intention semakin lemah.

Berdasarkan uraian di atas, dapat disimpulkan sementara melalui hipotesis penelitian sebagai berikut:

\section{$\mathbf{H}_{1 \mathrm{a}}$ :Affective Professional Commitment berpengaruh negatif terhadap turnover intention. \\ $\mathbf{H}_{1 \mathrm{~b}}$ :Continuance Professional Commitment berpengaruh negatif terhadap turnover intention. \\ $\mathrm{H}_{1 \mathrm{c}}$ :Normative Professional Commitment berpengaruh negatif terhadap turnover intention.}

\section{Hubungan antara Kepuasan Kerja dengan Turnover Intention} Individu yang merasa puas dengan pekerjaannya cenderung untuk bertahan dalam organisasi sedangkan individu yang merasa kurang puas dengan pekerjaannya akan memilih keluar dari organisasi (Witasari, 2009). Kepuasan kerja berkaitan dengan individu dalam melakukan pekerjaannya. Kepuasan kerja merupakan persepsi karyawan terhadap pekerjaannya tentang bagaimana pekerjaan tersebut dapat diselesaikan dengan baik (Luthans, 2006: 212).

Kepuasan kerja karyawan harus diperhatikan oleh organisasi. Turnover dalam suatu organisasi sering kali terjadi karena adanya ketidakpuasan kerja (Kalbers \& Cenker, 2007; Utami \& Bonosyaeni, 2009). Ketika karyawan merasa tidak puas terhadap pekerjaannya, maka keputusan keluar dari organisasi tersebut adalah pilihan yang diambil.

Penelitian tentang pengaruh kepuasan kerja terhadap turnover intention telah banyak dilakukan. Penelitian yang dilakukan oleh Bline etal. (1991); Kalbers \& Cenker (2007); Utami \& Bonosyaeni (2009) menunjukkan hasil bahwa kepuasan kerja berpengaruh negatif terhadap turnover intention. Hal tersebut menunjukkan bahwa semakin tinggi rasa puas karyawan terhadap perusahaan maka akan semakin rendah turnover intention. Begitu pula sebaliknya jika semakin rendah kepuasan karyawan terhadap perusahaan maka turnover intention semakin tinggi.

Berdasarkan uaraian di atas dapat disimpulkan hubungan antara kepuasan kerja dengan turnover intention adalah sebagai berikut:

$\mathbf{H}_{2}$ : Kepuasan kerja berpengaruh negatif terhadap turnover intention 


\section{Model penelitian}

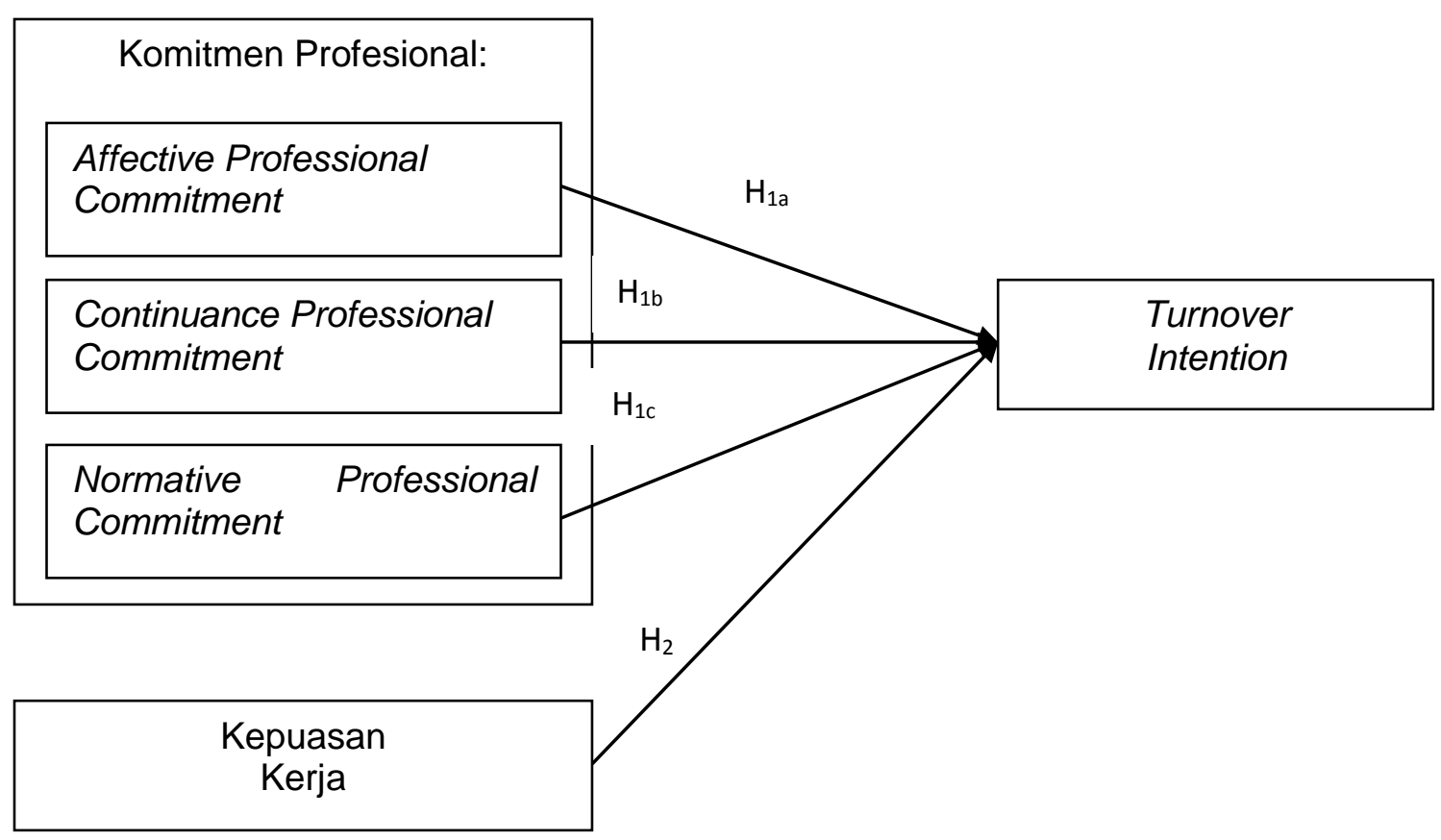

\section{METODE PENELITIAN}

\section{Populasi dan Sampel}

Populasi dalam penelitian ini adalah seluruh auditor yang bekerja pada Kantor Akuntan Publik (KAP) wilayah Jawa Timur. Terdapat 53 KAP di Jawa Timur yang digolongkan oleh peneliti kedalam 3 kelompok yaitu (1) KAP yang berafiliasi dengan Big 4, (2) KAP Nasional, dan (3) KAP Lokal (www.iapi.or.id). KAP yang berafiliasi dengn Big 4 adalah KAP yeng memiliki kerjasama dengan Big 4, KAP Nasional adalah KAP yang memiliki kantor cabang berskala nasional, sedangkan KAP Lokal adalah KAP yang tidak berafiliasi dengan Big 4 dan tidak memiliki kantor cabang skala nasional dan hanya berada pada suatu kota tertentu.

Peneliti memilih populasi penelitian KAP di wilayah Jawa Timur dengan pertimbangan bahwa KAP yang berada di Jawa Timur telah mampu merefleksikan KAP skala nasional karena di wilayah Jawa Timur terdapat KAP yang berafilisai dengan Big 4, KAP Nasional, dan KAP Lokal. Auditor di KAP yang menjadi subyek dalam penelitian ini adalah auditor yang belum maupun yang telah terdaftar di IAPI, serta dari berbagai jenjang karir yang meliputi (1) Junior Auditor, (2) Senior Auditor, (3) Manajer/ Supervisor, dan (4) Partner.

Pengambilan sampel dalam penelitian ini menggunakan desain convenience sampling. Pengambilan sampel jenis ini merupakan pengambilan sampel mudah dan dilakukan dengan sekehendak peneliti (Jogiyanto, 2004: 79). Pengambilan sampel dengan cara ini karena elemen populasi yang dipilih sebagai sampel adalah tidak diketahui dengan pasti jumlahnya. Identitas dari sampel juga tidak dapat diketahui dengan pasti, sehingga pengambilan sampel dengan teknik ini adalah yang paling tepat.

\section{Metode Pengumpulan Data}

Metode pengumpulan data yang digunakan dalam penelitian ini adalah metode surveiyaitu metode pengumpulan data primer dengan mengambil data dari populasi yang ada. Metode survei yang dipilih dalam penelitian ini adalah pengiriman kuesioner secara langsungke KAP di Jawa Timur. Metode 
pengumpulan data ini didukung dengan wawancara untuk mengkonfirmasi hasil penelitian.

\section{Definisi Operasional dan Pengukuran Vriabel}

\section{a. Komitmen Profesional}

Komitmen profesional yang dimaksud dalam penelitian ini menggunakan pendekatan multidimensi yang dikembangkankan oleh Smith \& Hall (2008).Komitmen profesional diukur dengan menggunakan item-item prtanyaan yang dikembangkan oleh Smith \& Hall (2008) dari instrumen penelitian Mayer \& Allen (1993) dengan mengganti poin profesi perawat dengan profesi akuntansi. Dalam penelitian ini diukur dengan menggunakan 6 item pertanyaan yang dikembangkan oleh Smith \& Hall (2008) untuk masingmasing Affective Professional Commitment (APC), Continuance Professional Commitment (CPC), dan Normative Professional Commitment (NPC) tanpa merubah poin dari pertanyaan.

\section{b. Kepuasan Kerja}

Kepuasan kerja berkaitan dengan individu dalam melakukan pekerjaannya. Kepuasan kerja merupakan persepsi karyawan terhadap pekerjaannya tentang bagaimana pekrjaan tersebut dapat diselesaikan dengan baik (Luthans, 2006: 212). Variable kepuasan kerja dalam penelitian ini diukur dengan menggunakan instrumen yang telah digunakan oleh Kalbers \& Cenker (2007) dan Pakawaru (2009) tanpa merubah poin dari pertanyaan.

\section{c. Turnover Intention}

Turnover intention merupakan niat individu untuk mencari alternatif pekerjaan lain (Pasewerk \& Strawse, 1996). Turnover intention diukur dengan menggunakan instrumen yang telah digunakan oleh Kalbers \& Cenker (2007) dan Pakawaru (2009) tanpa melakukan perubahan dalam poin pertanyaan.

\section{Metode Statistik}

Metode statistik yang digunakan untuk menguji hipotesis yang diajukan dalam penelitian ini adalah Partial Least Square (PLS) dengan bantuan program SmartPLS ver. 2.0 M3. PLS merupakan analisis persamaan struktural berbasis varian yang secara simultan dapat melakukan pengujian outer model dan inner model (Hartono etal. 2009: 14). Outer model digunakan untuk uji validitas dan reliabilitas, sedangkan inner model digunakan untuk uji kausalitas atau uji hipotesis(Hartono etal. 2009: 14).Bentuk persamaan struktural dalam penelitian ini adalah sebagai berikut:

$Y=-b_{1} X_{1}-b_{2} X_{2}-b_{3} X_{3}-b_{4} X_{4}+e$

Keterangan:

$\mathrm{Y}=$ turnover intention

$\beta=$ koefisien konstruk

$\mathrm{X}_{1}=$ affective professional commitment (APC)

$\mathrm{X}_{2}=$ continuance professional commitment $(C P C)$

$\mathrm{X}_{3}=$ normative professional commitmnet $(N P C)$

$\mathrm{X}_{4}=$ kepuasan kerja

$\varepsilon \quad=$ gangguan $/$ eror

\section{HASIL PENELITIAN}

\section{Evaluasi Model Hipotesis Penelitian}

Model penelitian ini terdiri dari lima konstruk yaitu turnover intention, affective professionl commitment, continuance professional commitment, normative professional commitment, dan kepuasan kerja. Evaluasi model dalam penelitian ini dilakukan melalui outer model dan inner model. Outer Model dievaluasi dengan menggunakan parameter AVE, Communality, Loading Factor, Cross Loading, Cronbach Alpha, dan Composite Reliability.Inner Model dievaluasi dengan menggunakan parameter $\mathrm{R}^{2}$ dan membandingkan antara $t$-statistics dengan t-table untuk pengujian hipotesis. 
Hasil OutputQuality Criteria Overview Model menggunakan SmartPLS

\begin{tabular}{lcccrrr}
\hline $\begin{array}{c}\text { Konstru } \\
\mathbf{k}\end{array}$ & $\begin{array}{c}\text { AV } \\
\mathbf{E}\end{array}$ & $\begin{array}{c}\text { Composit } \\
\mathbf{e} \\
\text { Reliabilit } \\
\mathbf{y}\end{array}$ & $\begin{array}{c}\mathbf{R} \\
\text { Squar } \\
\mathbf{e}\end{array}$ & $\begin{array}{c}\text { Cronbach } \\
\text { s Alpha }\end{array}$ & $\begin{array}{c}\text { Communalit } \\
\mathbf{y}\end{array}$ & $\begin{array}{c}\text { Redundanc } \\
\mathbf{y}\end{array}$ \\
\hline APC & 0.53 & 0.87 & & 0.82 & 0.53 & \\
CPC & 0.53 & 0.67 & & 0.39 & 0.53 & \\
KK & 0.43 & 0.83 & & 0.76 & 0.43 & \\
NPC & 0.57 & 0.89 & & 0.84 & 0.57 & \\
TI & 0.64 & 0.87 & 0.73 & 0.81 & 0.64 & 0.25 \\
\hline
\end{tabular}

Sumber: Data Primer Diolah

Berdasarkan table di atas dapat dilihat hasil uji reliabilitas serta uji validitas konvergen konstruk. Syarat suatu konstruk dinyatakan reliable adalah memiliki nilai cronbach alpha dan composite reliability $>0,6$, dan syarat suatu konstruk dinyatakan memiliki validitas konvergen adalah memiliki nilai AVE dan Communality yang lebih besar dari 0,5 dan nilai loadingfactor lebih besar dari 0,7. Tabledi atas menunjukkan bahwa terdapat satu konstruk yang memiliki nilai cronbach alpha dan composite reliability kurang dari 0,6 yaitu Continuance Professional Commitment (CPC), selain itu nilai AVE dan Communality pada konstruk kepuasan kerja (KK) kurang dari 0,5. Dengan demikian, konstruk CPC merupakan kostruk yang tidak reliable dan konstruk KK merupakan konstruk yang tidak memenuhi syarat validitas. Untuk meningkatkan reliabilitas serta validitas konstruk, peneliti akan menghapus indikator yang tidak valid.

Hasil Output Quality Criteria Overview Algoritma Model menggunakan SmartPLS Setelah Modifikasi Indikator

\begin{tabular}{lrrrrrr}
\hline & AVE & $\begin{array}{c}\text { Composite } \\
\text { Reliability }\end{array}$ & $\begin{array}{c}\text { R } \\
\text { Square }\end{array}$ & $\begin{array}{c}\text { Cronbachs } \\
\text { Alpha }\end{array}$ & Communality & Redundancy \\
\hline APC & 0.53 & 0.87 & & 0.82 & 0.53 & \\
CPC & 0.68 & 0.89 & & 0.84 & 0.68 & \\
KK & 0.52 & 0.84 & & 0.77 & 0.52 & \\
NPC & 0.65 & 0.90 & & 0.87 & 0.65 & \\
TI & 0.64 & 0.87 & 0.75 & 0.81 & 0.64 & 0.25 \\
\hline
\end{tabular}

Sumber: data primer diolah

Table di atas menunjukkan bahwa nilai AVE, Composite Reliability, Cronbachs Alpha, Communality, dan Cross Loading telah memenuhi criteria. Dengan demikian dapat disimpulkan bahwa data penelitian telah valid dan reliable untuk dilakukan pengujian berikutnya.

\section{Evaluasi Inner Model}

Pengujian inner model dievaluasi dengan menggunakan nilai $\mathrm{R}^{2}$ dan uji signifikansi melalui nilai koefisien path atau t-values setiap path. Nilai $\mathrm{R}^{2}$ menggambarkan seberapa besar variabel laten dependen dapat dipengaruhi oleh variabel laten independennya. Berikut ini adalah output model structural yang menunjukkan besarny nilai $\mathrm{R}^{2}$ : 


\section{Output Inner Model}

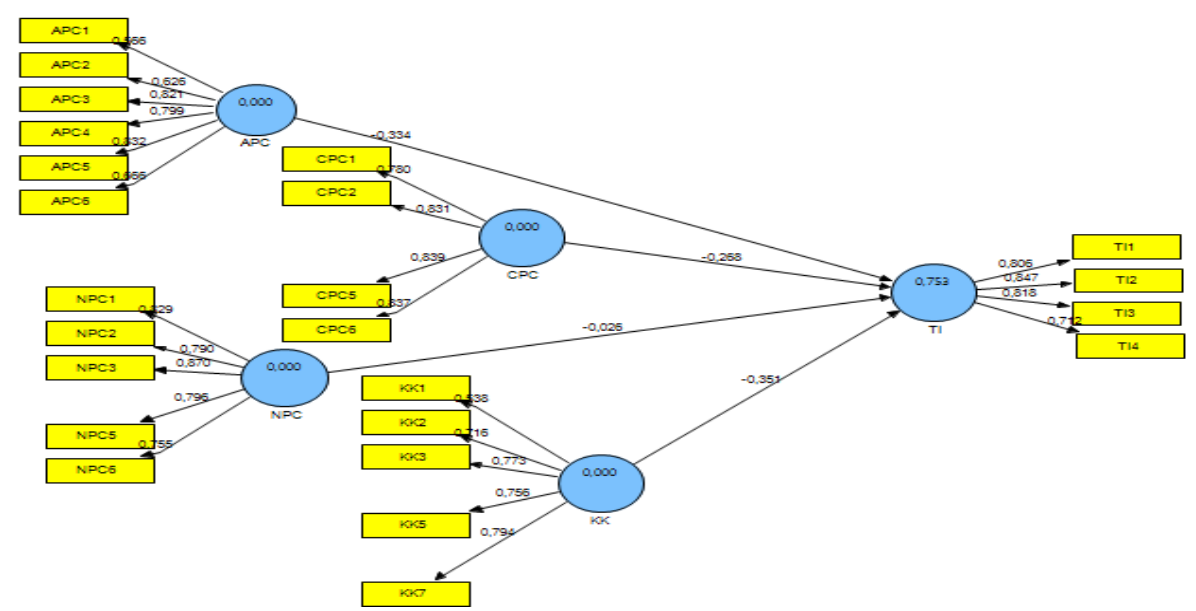

Berdasarkan gambar di atas dapat dilihat bahwa nilai $\mathrm{R}^{2}$ adalah 0,75 . Hal tersebut menjelaskan bahwa konstruk turnover intention dapat dijelaskan melalui konstruk Affective Professional Commitment, Continuance Professional Commitment, Normative Professional Commitment, dan Kepuasan Kerja sebanyak $75 \%$ dan sisanya $25 \%$ dijelaskan melalui variable lain diluar model yang diajukan dalam penelitian ini.Selain $\mathrm{R}^{2}$ pengujian model struktural atau inner model dievaluasi menggunakan uji signifikansi. Berikut ini adalah hasil uji signifikansi nilai koefisien path atau $t$-values setiap path:

Hasil Output Bootstraping

\begin{tabular}{lcccccc}
\hline \multicolumn{1}{c}{ Hipotesis } & $\begin{array}{c}\text { Original } \\
\text { Sample } \\
(\mathbf{O})\end{array}$ & $\begin{array}{c}\text { Sample } \\
\text { Mean (M) }\end{array}$ & $\begin{array}{c}\text { Standard } \\
\text { Deviation } \\
\text { (STDEV) }\end{array}$ & $\begin{array}{c}\text { Standard } \\
\text { Error } \\
(\text { STERR) }\end{array}$ & $\begin{array}{c}\text { T Statistics } \\
(\mid \mathbf{O S T E R R | )})\end{array}$ & Keputusan \\
\hline (H1a) APC-> TI & -0.333607 & -0.367705 & 0.132947 & 0.132947 & 2.509318 & Diterima \\
(H1b) CPC -> TI & -0.268195 & -0.265614 & 0.13347 & 0.13347 & 2.009405 & Diterima \\
(H1c) NPC -> TI & -0.025922 & -0.012752 & 0.231522 & 0.231522 & 0.111963 & Ditolak \\
(H2) KK -> TI & -0.351466 & -0.339398 & 0.145045 & 0.145045 & 2.423154 & Diterima \\
\hline
\end{tabular}

Sumber: Data primer diolah

Uji signifikansi di dapatkan melalui perbandingan $t$-statistic dengan $t$-table. Hipotesis yang dibangun dalam penelitian ini adalah menggunakan hipotesis satu ekor (one-tailed). T-table untuk hipotesis dua ekor adalah >1,64. Berdasarkan table di atas dapat disimpulkan bahwa $\mathrm{H}_{1 \mathrm{a}}, \mathrm{H}_{1 \mathrm{~b}}$, dan $\mathrm{H}_{2}$ diterima.

\section{Diskusi hasil}

a. Hipotesis Affective Professional Commitment Terhadap Turnover Intention

Berdasarkan hasil pengujian yang dilakukan terhadap konstruk Affective
Professional Commitment dan Turnover Intention menunjukkan bahwa semakin besar Affective Professional Commitment, maka Turnover Intention semakin rendah. Smith \& Hall (2008) mendefinisikan Affective Professional Commitment adalah komitmen yang terjadi ketika auditor ingin menjadi bagian dari profesi karena adanya keinginan untuk mencapai tujuan profesi. Turnover intention adalah keinginan atau niat auditor untuk berhenti dari profesinya (Witasari, 209). Oleh karena itu, penelitian ini membuktikan bahwa auditor yang 
memiliki rasa ikut memiliki pada profesi, rasa terikat secara emosional pada profesi serta merasa menjadi bagian dari profesi maka keinginan untuk berpindah dari profesi rendah.

Hasil wawancara yang dilakukan oleh peneliti terhadap beberapa auditor yang bekerja di KAP menunjukkan bahwa auditor telah memiliki Affective Professional Commitment yang tinggi. Hal tersebut ditunjukkan oleh jawaban auditor yang mengungkapkan bahwa mereka menyukai profesi yang dijalani saat ini, selain itu mereka menyebutkan bahwa ingin menjadi bagian dari profesi auditor dan ingin memiliki masa depan yang baik sebagai auditor. Dengan demikian, semakin tinggi komitmen auditor berdasarkan emosionalnya maka keinginan untuk berpindah akan semakin kecil.

Hasil penelitian ini sesuai dengan yang diprediksi oleh teori bahwa dengan semakin besar komitmen pribadi untuk menjadi bagian dari profesi akan semakin menekan keinginan auditor untuk berpindah dari profesinya (Smith \& Hall, 2008 dan Kalbers \& Cenker, 2007). Hasil penelitian ini mendukung hasil penelitian Smith \& Hall (2008),Kalber \& Fogarty (1995), Kalbers \& Cenker (2007), dan Pakawaru (2009)yang membuktikan bahwa Affective Professional Commitment dan Turnover Intention dapat menjelaskan auditor memiliki keinginan untuk berpindah.

b. Pengaruh Continuance Professional Commitment terhadap Turnover Intention

Berdasarkan hasil pengujian terhadap konstruk Continuance Professional Commitment dan Turnover Intention menunjukkan bahwa semakin besar Continuance Professional Commitment, maka dapat menekan terjadinya turnover intention. Simth \& Hall (2008) mendefinisikan Continuance Professional Commitment sebagai keinginan karyawan untuk tetap bertahan pada profesinya, karena tidak ada alternatif pekerjaan lain. Oleh karena itu, penelitian ini membuktikan bahwa keingian auditor untuk berpindah dari profesinya, karena adanya alternatif pilihan pekerjaan yang lain.

Hasil wawancara yang dilakukan oleh peneliti terhadap auditor yang bekerja di KAP menunjukkan bahwa auditor telah memiliki Continuance Professional Commitment yang tinggi. Hal tersebut ditunjukkan oleh jawaban auditor atas pertanyaan-pertanyaan yang diajukan oleh peneliti. Beberapa jawaban yang menunjukkan adanya Continuance Professional Commitment adalah bahwa auditor masih belum menemukan alternatif pekerjaan lain yang dirasa sesuai, selain itu auditor merasa membutuhkan gaji yang diterimanya untuk memenuhi kebutuhan hidupnya, sehingga auditor tidak memutuskan untuk berpindah.

Hasil penelitian ini sesuai dengan yang diprediksi oleh teori bahwa dengan semakin besarnya komitmen karena tidak adanya alternatif pekerjaan lain akan semakin menekan keinginan auditor untuk berpindah dari profesinya (Pakawaru, 2009). Penelitian ini mendukung hasil penelitian Pakawaru (2009) dan Kalber \& Fogarty (1995) bahwa Continuance Provessional Commitment berpengaruh negatif terhadap Turnover Intention. Penelitian ini membuktikan bahwa hubungan Continuance Professional Commitment dan Turnover Intention dapat menjelaskan mengapa auditor memiliki keinginan untuk berpindah.

\section{c. Pengaruh Normative Professional Commitment terhadap Turnover Intention}

Berdasarkan hasil pengujian terhadap konstruk Normative Professional Commitment terhadap turnover Intention menunjukkan bahwa turnover intention tidak ditentukan oleh Normative Provessional Commitment. Smith \& Hall (2008) mendefinisikan 
Normative Professional Commitment merupakan komitmen yang didasari adanya kewajiban untuk berkomitmen. Dengan demikian, keinginan auditor untuk berpindah dari profesinya bukan karena rendahnya komitmen yang di dasari oleh kewajiban untuk tetap bertahan pada profesi auditor.

Normative

Professional

Commitment timbul dari nilai-nilai diri auditor yang beratahan pada profesinya karena kesadaran bahwa berkomitmen terhadap profesi merupakan suatu keharusan atau kewajiban (Susanto \& Gunawan, 2013). Auditor bertahan pada profesinya karena merasa sudah seharusnya melakukan hal tersebut. Kewajiban untuk tetap bertahan pada profesi auditor biasa terjadi karena investasi organisasi atau profesi terhadap auditor, misalnya pelatihan atau subsidi kuliah.

Berdasarkan hasil interview yang dilakukan peneliti terhadap beberapa auditor, ditemukan beberapa alasan yang menunjukkan kurangnya komitmen yang didasarkan atas kewajiban. Pertama, auditor menyebutkan bahwa pada KAP tidak terdapat program subsidi studi maupun training yang mengikat pesertanya, sehingga auditor merasa tidak berkewajiban untuk tetap mengabdi pada profesinya sebagai auditor di KAP. Kedua, auditor menyebutkan bahwa untuk tetap bekerja pada KAP tidak ada tekanan dari pihakpihak tertentu baik dari dalam maupun dari luar KAP. Dengan demikian, keinginan auditor untuk bertahan pada profesinya tidak disebabkan oleh komitmen karena kewajiban yang timbul atas subsidi dari KAP maupun tekanan dari suatu puhak tertentu melainkan disebabkan oleh komitmen yang didasari oleh ikatan emosional dan komitmen karena tidak ada alternatif pekerjaan lain.

Hasil penelitian ini mendukung hasil penelitian Smith \& Hall (2008) dan Kalbers \& Cenker (2007). Smith \& Hall
(2008) berpendapat bahwa turnover intention tidak dipengaruhi oleh Normative Professional Commitment karena hanya sebagian kecil KAP yang mewajibkan auditor untuk mengabdi pada KAP atas pelatihan yang telah diberikan, sehingga Normative Professional Commitment tidak memiliki hubungan kuat dengan turnover intention.

\section{d. Pengaruh \\ Kepuasan Kerjaterhadap Turnover Intention} Berdasarkan hasil pengujian terhadap konstruk Kepuasan Kerja dan Turnover Intention menunjukkan bahwa semakin tinggi kepuasan kerja, maka akan menekan tingkat turnover intention. Khanifar (2012) mendefinisikan kepuasan kerja sebagai seperangkat perasaan karyawan tentang menyenangkan atau tidaknya pekerjaan yang mereka jalankan. Kepuasan kerja sangat penting karena menyumbang keberhasilan perusahaan, antara lain meningkatkan produktivitas serta dapat menurunkan tingkat absensi (Sidharta \& Margaretha, 2011). Hasil wawancara yang dilakukan oleh peneliti terhadap beberapa auditor menjunjukkan bahwa auditor telah memiliki kepuasan terhadap pekerjaannya. Oleh karena itu, semakin auditor merasa puas terhadap hasil kerjanya, maka dapat mengurangi keinginannya untuk mencari alternatif pekerjaan lain ataupun meninggalkan pekerjaannya.

Hasil penelitian ini sesuai dengan prediksi teori yaitu individu yang merasa puas dengan pekerjaannya cenderung untuk bertahan dalam pekerjaannya, sedangkan individu yang kurang puas dengan pekerjaannya akan memilih mengundurkan diri (Witasari, 2009). Hasil penelitian ini mendukung hasil penelitian Kalbers \& Cenker (2007), Utami \& Bonosyeani (2009), Sidharta \& Margaretha (2011) yang membuktikan hubungan Kepuasan Kerja dan Turnover Intention dapat menjelasakan keinginginan auditor untuk berpindah. 
V. KESIMPULAN, KETERBATASAN, DAN SARAN

\section{Kesimpulan}

Penelitian ini bertujuan untuk membuktikan hubungan komitmen profesional dan kepuasan kerja terhadap turnover intention. Variable komitmen profesional terdiri dari tiga dimensi yaitu Affective Professional Commitment, Continuance Professional Commitment, dan Normative Professional Commitment. Sampel penelitian ini adalah auditor yang bekerja di kantor akuntan publik di Jawa Timur. Jumlah sampel yang didapatkan dalam penelitian ini adalah sebanyak 85, namun 6 diantaranya tidak dapat dimasukkan dalam pengujian, karena merupakan sampel bias atau tidak lengkap. Dengan demikian jumlah sampel yang diuji adalah sebanyak 79 sampel. Model analisis data dalam penelitian ini adalah Partial Least Square dengan bantuan program SmartPLS ver. 2.0 M3.

Hasil penelitian ini adalah turnover intention pada KAPditentukan oleh komitmen professional yang terdiri dari affective professional commitment dan continuance professional commitment, serta kepuasan kerja auditor. Affective professional commitment yang rendah dapat menyebabkan turnover intention, dengan demikian keinginan auditor untuk berpindah dikarenakan kurangnya rasa memiliki auditor terhadap profesinya. Continuance professional commitment yang rendah terbukti dapat meningkatkan turnover intention, sehingga keinginan auditor untuk berpindah dikarenakan adanya alternatif pilihan profesi lain. Turnover intention juga ditentukan oleh kepuasan kerja, semakin rendah tingkat kepuasan kerja auditor meningkatkan keinginan auditor untuk berpindah.

Penelitian ini tidak berhasil membuktikan bahwa turnover intention ditentukan oleh normative professional commitment. Dengan demikian, keinginan auditor untuk berpindah bukan disebabkan oleh tidak adanya kewajiban untuk mengabdi kepada KAP. Turnover intention tidak dapat ditentukan oleh Normative professional commitment dikarenakan pada KAP sebagai subyek penelitian belum terdapat program subsidi studi maupun pelatihan yang mewajibkan auditor untuk megabdi setalah mendapatkan subsidi maupun pelatihan tersebut, sehingga auditor tidak merasa memiliki kewajiban untuk tetap bertahan.

\section{Keterbatasan dan saran}

Peneliti menyadari terdapat keterbatasan dalam penelitian ini. Pertama, variable kepuasan kerja penelitian ini tidak dibedakan ke dalam berbagai dimensi, misalnya kepuasan kerja yang didasari atas memadainya gaji yang diperolah. Hal tersebut dikarenakan informasi mengenai dimensi yang menentukan kepuasan kerja sulit untuk didapatkan. Keterbatasan kedua, kurang banyaknya KAP yang bekerjasama untuk penelitian ini. Hal tersebut dikarenakan kesibukan di KAP yang bertepatan dengan masa audit tengah tahunan, sehingga hanya sebagian KAP yang bersedia bekerjasama. Ketiga, jumlah sampel penelitian yang relatif sedikit walaupun telah memenuhi batas minimal, yang tentunya mempengaruhi keandalan pengujian data. Keterbatasan yang keempat berkaitan dengan kompleksitas masalah turnover intention, sehingga terdapat beberapa pengaruh faktor lain yang belum dipertimbangkan dalam model yang diteliti.

Saran peneliti untuk topik dan subyek penelitian yang sama adalah pertama, peneliti disarankan menggali lebih dalam dimensi dari kepuasan kerja sehingga memungkinkan untuk membagi variable kepuasan kerja dalam beberapa dimensi yang lebih spesifik. Kedua, peneliti dapat mempertimbangkan waktu penelitian yang tepat, sehingga tidak 
bertepatan dengan kesibukan auditor di KAP. Alasan peneliti memberikan saran ini adalah untuk mendapatkan tingkat respon yang tinggi dari auditor di KAP. Ketiga, peneliti berikutnya dapat mempertimbangkan perlunya tanda terimakasih yang diberikan di awal penyebaran kuesioner, sehingga diharapkan dapat meningkatkan tingkat

\section{Referensi}

Amilin \& Dewi. Rosita, Pengaruh Komitmen Organisasi terhadap Kepuasan Kerja Akuntan Publik dengan Role Stress sebagai Variabel Moderating, Jurnal UIN Syarif Hidayatullah.

Bline. D. M., D. Duchon, \& W. F. Meixner, The measurement of organizational and professional commitment: An examination of the psychometric properties of two commonly used instruments, Behavioral Research in Accounting, Vol 3, 1991.

Cho. Vincent \& Huang, Xu, Professional commitment, organizational commitment, and the intention to leave for professional advancement: An empirical study on IT professional, Information Technology \& People. Vol.25(1), 2012.

Jogiyanto. Hartono, Metodologi Penelitian Bisnis: Salah Kaprak dan Pengalaman-Pengalaman (Yogyakarta: Bpfe, 2004).

Hartono. Jogiyanto \& Willy Abdillah, Konsep dan Aplikasi PLS (Partial Least Square) untuk Penelitian Empiris (Yogyakarta, Andi, 2009).

Hollenbeck. Jr., \& C. R. Williams, "Turnover Functionality versus Turnover Frequency: A Note on Work Attitudes and Organizational Effectivenes", Journal of Applied Psychology, Vol 71, 1986, 606-611.

Kalbers. Lawrence. P. \& Cenker William. J, Organizational respon. Saran keempa, peneliti selanjutnya dapat mempertimbangkan faktor-faktor lain yang kemungkinan mempengaruhi turnover intention sehingga penelitian tentang turnover intention dapat berkembang. Faktor tersebut misalnya kondisi perekonomian makro yang fluktiatif, sehingga mempengaruhi turnover intention.

commitment and auditors in public accounting, Managerial Auditing Journal, Vol 22(4), 2007, 354-375.

Kalbers. Lawrence. P. \& Fogarty. T.J, Professionalism and Its Consecuences: A Study of Internal Auditors, A Journal of Practice \& Theory, Vol. 14, 1995, 64-86.

Khanifar. Hossein, Analysis of Job Satisfaction and Professional Commitment between Staffs, Journal of Basic and Applied Scientific Research, Vol 2(7), 2012, 6424-6429.

Luthans. Fred, Organizational Behavior (New York: McGraw-Hill, 2005).

Pakawaru. Irham, Komitmen Organisasi dan Kepuasan Kerja Sebagai Prediktor Keinginan Auditor Untuk Berpindah, Thesis, Brawijaya University, Malang, 2009.

Pasewark. William.R. \& Strawser. Jerry. $\mathrm{R}$, The Determinants and Outcomes Associated with Job Insecurity in a Professional Accounting Environment, Behavioral Research in Accounting, Vol 8, 1996.

Poznanski. Peter. J. \& Bline. Dennis. M, Using Structural Equation Modeling to Investigate the Causal Ordering of Job Satisfaction and Organizational Commitment Among Staff Accountants, Behavioral Research in Accounting, Vol 9, 1997.

Robbins. Stephen. P \& Pujaatmaka. Hadyana, Perilaku Organisasi (Konsep, Kontroversi, Aplikasi) (Jakarta: Prenhallindo, 1996). 
Robbins. Stephen. P, Organizational Behavior ( New Jersey: PrenticeHall International, 2001).

Sidharta. Novita \& Margaretha. Meily, Dampak Komitmen Organisasional dan Kepuasan Kerja Terhadap Turnover Intention: Studi empiris pada karyawan bagian operator di salah satu perusahaan garment di Cimahi. Jurnal Manajemen, Vol 10(2), 2011.

Smith. D. \& Hall. M, An Empirical Examination of a Three Component Model of Professional Commitment among Public Accountants, Behavioral Research In Accounting, Vol 20(1), 2008.

Susanto. Eddy. M. \& Gunawan. Carin, Kepuasan Kerja, Komitmen Organisasional dan Turnover Intention, Jurnal Mitra Ekonomi dan Manajemen Bisnis, Vol 4(1), 2013, 76-88.

Toly. Agus. A, Analisis Faktor-Faktor yang Mempengaruhi Turnover
Intention pada Staf Kantor Akuntan Publik, Jurnal Akuntanssi \& Keuangan, Vol 5(2), 2001.

Trisnaningsih. Sri, Pengaruh Komitmen terhadap Kepuasan Kerja Auditor: Motivasi sebagai Variabel Intervening (Studi Empiris pada Kantor Akuntan Publik di Jawa Timur,. Thesis, Diponegoro University, Semarang, 2001.

Utami. I \& Bonosyeani. N.E.S, Pengaruh Job Insecurity, Kepuasan Kerja, dan Komitmen Organisasional terhadap

Keinginan Berpindah, Jurnal Akuntansi \& Keuangan Indonesia. Vol 6(1), 2009.

Witasari. Lia, Analisis Pengaruh Kepuasan Kerja dan Komitmen Organisasional terhadap Turnover Intention (Studi Empiris pada Novotel Semarang). Thesis. Diponegoro University. Semarang, 2009.

http://www.iapi.or.id/iapi/directory.php 